\title{
Effect of Slab Stiffness on EBF Link Rotation Demands and Implications for Link Ultra Low-Cycle Fatigue Susceptibility
}

\author{
G.S. Prinz ${ }^{1}$ and A. de Castro-e-Sousa ${ }^{2}$ \\ ${ }^{1}$ Assistant Professor, Department of Civil Engineering, University of Arkansas, 4190 \\ Bell Eng. Center, Fayetteville, AR 72701; (479) 575-2494; email: prinz@uark.edu \\ ${ }^{2}$ PhD Candidate, Steel Structures Laboratory (ICOM), Swiss Federal Institute of \\ Technology (EPFL), GC B3 465 Station 18, 1015 Lausanne, Switzerland; +41 (0)21 \\ 693-2430; email: albano.sousa@epfl.ch
}

\begin{abstract}
This study aims to quantify slab contributions in eccentrically braced frames (EBFs) by investigating the dynamic performance of two 3-story EBF configurations with and without concrete slabs: one configuration having long (flexural yielding) links and the other having shorter (shear yielding) links. Particular effort is spent investigating the relative accumulation of ultra low-cycle fatigue damage within the link regions during dynamic loading. All slab and major frame geometries are modeled using shell elements. Linear springs and nodal constraints model the discrete slab-to-beam interactions. Recorded earthquake ground accelerations, scaled to design-level intensities, load the EBFs. Ultra low-cycle fatigue damage is investigated using a calibrated micro-mechanics based ductile fracture model. Results indicate reduced system-level frame demands (inter-story drift, residual drift, and link rotation) due to increased system stiffness from the concrete slabs. Reductions in these demands were larger for EBFs with long (flexural yielding) links as compared to the short (shear yielding) links. Even with reduced rotation demands, EBF models with slabs sustained similar link fatigue damage, as compared with the bare-steel models, due to increased plastic strain demands presumably from a neutral axis shift.
\end{abstract}

\section{INTRODUCTION}

Steel eccentrically braced frame (EBF) systems are specially designed to dissipate seismic loads by localizing plastic deformations within detailed beam regions, called active links. Since beams in steel framed buildings are usually connected to concrete slabs, the behavior of these active links during dynamic earthquake loading may be directly influenced by the beam-to-slab composite action.

Experimental testing of bare-steel and composite shear links (having link-tocolumn connections) by Popov and Ricles (1988) indicates a near 10\% increase in elastic stiffness for composite links over bare-steel links. Additionally, the slab-tobeam interactions outside of the link regions remained essentially elastic, even during large link rotations. Long links were not considered and slab effects on EBF systemlevel performance were not determined.

Observed damage following the 2010-2011 Christchurch earthquake series indicates better-than-expected dynamic performance for EBFs, with contributions 
from the concrete slabs assumed to be a key contributor (Clifton et al., 2011; Gardiner et al., 2013). It is important to note that the Christchurch events provided the most intense earthquake shaking for EBF systems to date. Inspection of a 22-story EBF structure following the February 2011 event revealed shear yielding (evidenced by diagonal Luder lines) in many of the EBF links; however, the majority of link yielding was minor and it was concluded that enough reserve capacity remained to withstand another ultimate limit state event (Gardiner et al., 2013). Measured residual drifts were low (less than $0.3 \%$ ) and slab cracking was concentrated near link regions, though cracking was not as bad as anticipated under a code level event. One link was later found to have fractured, presumably under low-cycle fatigue from later shaking events which continued throughout the year. Similar EBF performance was observed in other Christchurch structures (Clifton et al., 2011).

Because link rotations in an EBF system are partially aided by shortening of the frame bay width, added stiffness through slab membrane action may help reduce link rotation demands (see Figure 1). Additionally, elastic out-of-plane slab stiffness outside the link regions may help reduce residual frame drifts, providing a kind of self-centering behavior. While several analytical studies have investigated seismic demands in EBF systems and components (Ricles and Popov, 1994; Richards and Uang, 2006; Richards, 2009; Kanvinde et al., 2012), the majority of these studies either neglect the concrete slabs or replace the concrete slabs by rigid-diaphragm constraints.
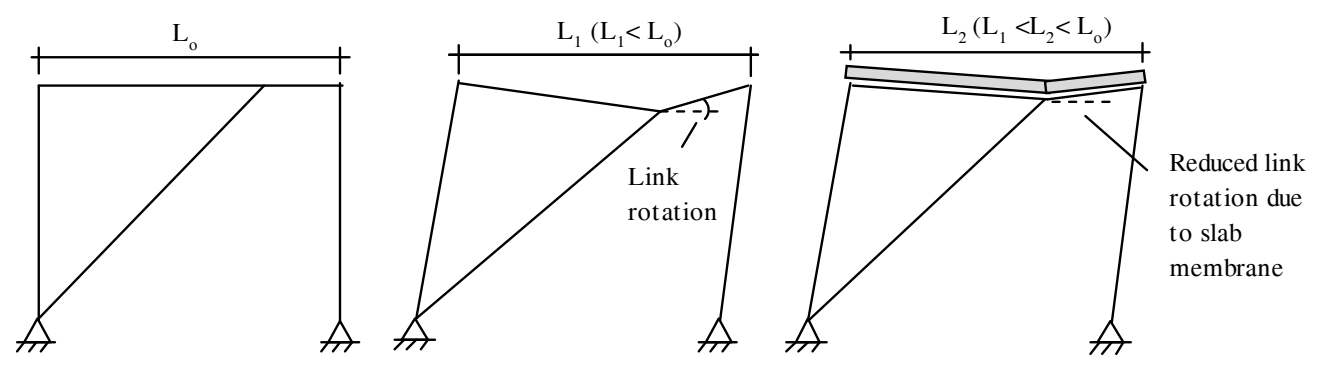

Figure 1. Potential bay-shortening effects between composite and bare-steel EBFs.

This paper uses validated finite element modeling techniques to compare the relative seismic demands in several EBFs with and without concrete slabs. EBFs with both flexural-yielding and shear-yielding links in link-to-column configurations are considered. Concrete slabs and the slab-to-frame interactions are explicitly modeled. The paper begins by describing the various methods used, including: the chosen prototype EBF designs, modeling techniques, and applied loads. Then, the relative slab effects on EBF link rotation demands, peak and residual story drift, and lowcycle fatigue damage within the link regions are presented.

\section{METHODS}

Prototype EBF Designs. Two 3-story EBFs, one designed with short shear-yielding links $\left(e<1.6 \cdot \mathrm{M}_{\mathrm{p}} / \mathrm{V}_{\mathrm{p}}\right)$ and the other designed with longer flexural-yielding links $\left(\mathrm{e}>2.6 \cdot \mathrm{M}_{\mathrm{p}} / \mathrm{V}_{\mathrm{p}}\right)$, are used in this study to gain insights into slab effects on each link type. Member sizes for the prototype frames are taken from designs presented in 
Richards (2004) and summarized in Table 1. The designs are based on earthquake demands within southern California region (see Richards (2004) for the design response spectrum). Figure 2 shows the two EBF configurations, all having link-tocolumn connections. Link detailing (link stiffener spacing and sizing) follows requirements outlined in the AISC seismic design guidelines (AISC, 2005). Each EBF design is considered as both a bare-steel system and system with a concrete slab, creating a total of four frames for the dynamic study. All concrete slabs are assumed to be four inches thick with $0.333 \mathrm{in}^{2} / \mathrm{ft}$ of steel reinforcement located on the underside (representing the steel decking), and have an effective width based on the building geometry in Figure 2.

The prototype buildings assume a total seismic weight of 5745 kips distributed as 2030 kips at each floor and 1685 kips at the roof.

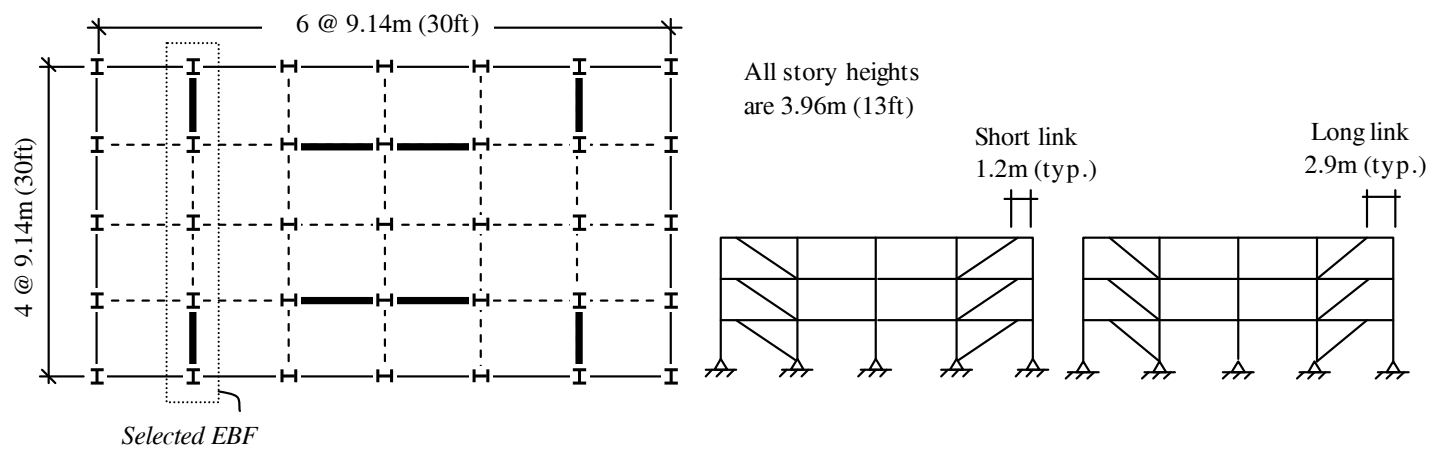

Figure 2. Plan and elevation views of prototype EBF configurations

Table 1: EBF member sizes

\begin{tabular}{|c|c|c|}
\hline \multirow[b]{2}{*}{ Member } & \multicolumn{2}{|c|}{ Shape (U.S. designation) } \\
\hline & Short Link Frame & Long Link Frame \\
\hline $\mathrm{BM} 1^{\mathrm{a}}$ & $\mathrm{W} 16 \times 77$ & W30x108 \\
\hline $\mathrm{BM} 2$ & $\mathrm{~W} 14 \times 74$ & W24x84 \\
\hline BM3 & $\mathrm{W} 10 \times 45$ & W18x85 \\
\hline $\mathrm{BR} 1^{\mathrm{b}}$ & HSS16x16x 5/8 & W14x283 \\
\hline BR2 & HSS $14 \times 14 x$ 5/8 & HSS $16 \times 16 \times 5 / 8$ \\
\hline BR3 & HSS $12 \times 12 \times 1 / 2$ & HSS $12 \times 12 \times 5 / 8$ \\
\hline CL1-CL3 ${ }^{\mathrm{c}}$ & $\mathrm{W} 14 \times 61$ & $\mathrm{~W} 14 \times 257$ \\
\hline $\mathrm{CR} 1-\mathrm{CR} 3^{\mathrm{d}}$ & $\mathrm{W} 14 \times 90$ & $\mathrm{~W} 14 \times 257$ \\
\hline $\begin{array}{l}\text { a. BM1 is bea } \\
\text { b. BR1 is first } \\
\text { c. CL1 is first } \\
\text { d. CR1 is first }\end{array}$ & $\begin{array}{l}\text { a. BM1 is beam at first story, BM2 is beam at second story... } \\
\text { b. BR1 is first story brace, BR2 is second story... }\end{array}$ & ond story... \\
\hline
\end{tabular}

Modeling Techniques. To reduce computational cost, only one 3-story EBF section of the prototype building is modeled, carrying one quarter of the entire building seismic mass. This seismic mass is lumped at the columns of each story. To account for P- $\Delta$ effects, a single continuous column is added to the models, representing all 
gravity columns associated with the frames (one quarter of the building gravity columns). The stiffness and strength of the P- $\Delta$ column is equal to the sum of the individual gravity columns, considering weak axis bending. This technique is similar those used in other dynamic studies (Chi et al., 1998; Tremblay and Robert, 2001; Foutch and Yun, 2002; Richards, 2009). Figure 3 shows the short-link model boundary conditions, with available degrees of freedom highlighted (boundary conditions for the long-link model are the same). From Figure 3, the base of each EBF column is pinned, and out-of-plane beam deformation outside the link is restrained (representing lateral beams framing in). Column twisting is also restrained at each floor level, accounting for beams framing into the column from all directions. The P- $\Delta$ column is pinned at the base, and rigidly constrained to match the frame deformation at each floor.

Two percent Rayleigh damping is specified from the first and third vibration modes of each frame. To determine the modal frequencies used in calculation of the Rayleigh damping parameters, frequency analyses were conducted on each EBF model. Table 2 presents the first three vibration frequencies for each model used to calculate the corresponding $\alpha$ and $\beta$ values (from the Rayleigh relationship $\zeta_{\mathrm{i}}=\alpha / 2 \cdot \omega_{\mathrm{i}}$ $\left.+\beta \cdot \omega_{i} / 2\right)$ used in the ABAQUS analyses. From Table 2, a slight increase in the fundamental frequency value is noticed for the EBF models containing concrete slabs. This increase in frequency indicates an increase in system stiffness, which is not surprising.

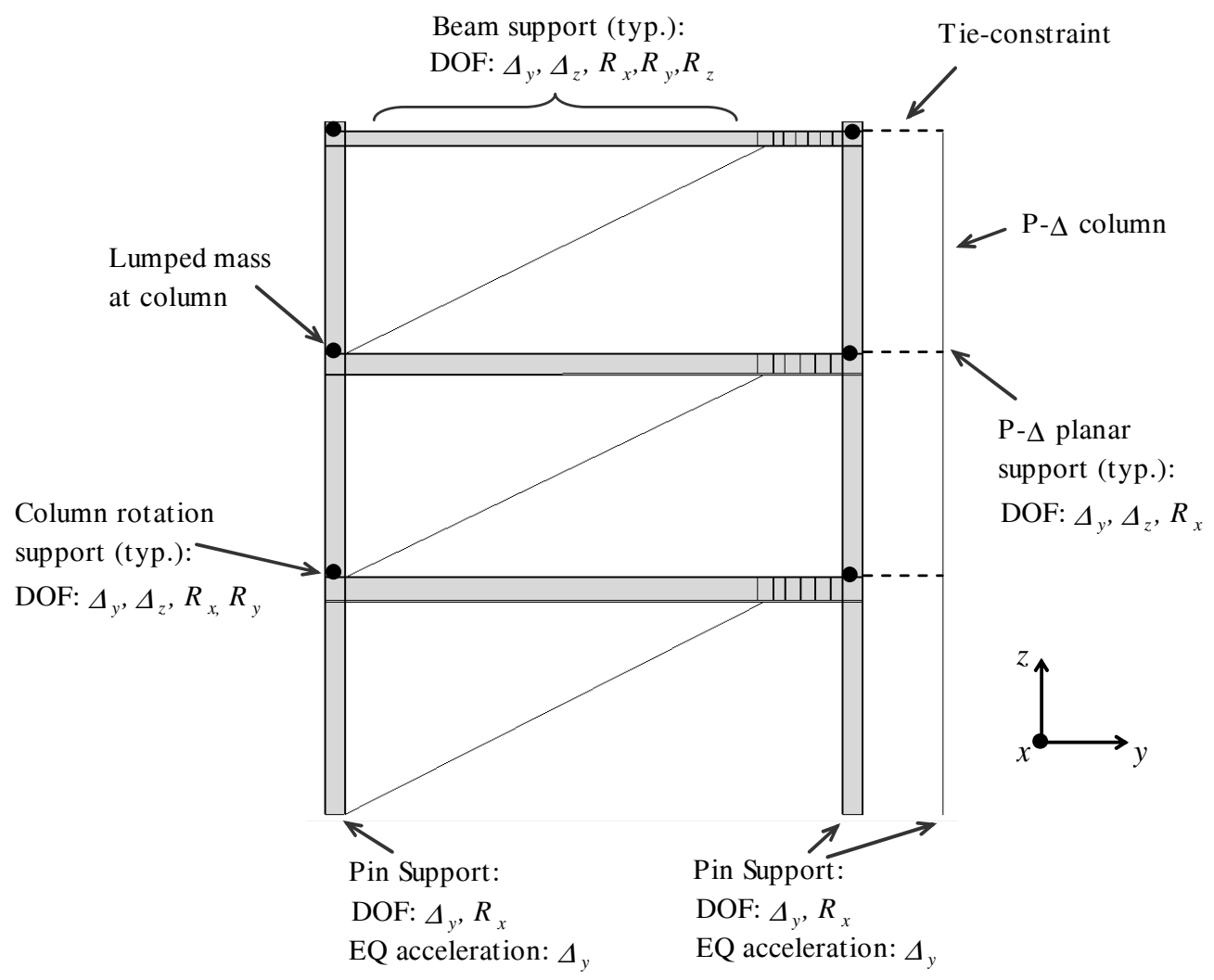

Figure 3. Model boundary constraints (available DOF shown). 
Table 2: EBF frequency values for modes 1, 2, and 3

\begin{tabular}{ccccc}
\cline { 2 - 5 } & \multicolumn{3}{c}{ Vibration Frequency (Hz) } \\
\cline { 2 - 5 } Mode & Slab & No Slab & Slab & No Slab \\
\hline 1 & 1.42 & 1.26 & 1.54 & 1.36 \\
2 & 3.43 & 3.19 & 4.08 & 3.71 \\
3 & 4.23 & 4.07 & 6.98 & 6.59 \\
\hline
\end{tabular}

Four-node linear shell elements with reduced integration (element S4R in ABAQUS) model all beams, columns, link stiffeners, and slabs. A general mesh size of $2 \mathrm{in}$. is used for all steel members, while a general mesh size of 5in. is used for the concrete slabs. To further reduce computation time, braces and the P- $\Delta$ gravity column are modeled using linear beam elements. Nonlinear geometry effects are considered in the analyses.

Nonlinear steel material properties were assigned to the EBF members. The steel material plasticity was based on a von Mises yield surface with an associated flow rule. Material hardening was determined using a nonlinear kinematic hardening law with parameters calibrated from cyclic coupon test data presented in Kaufmann et al. (2001).

Modeling for the concrete slab followed techniques similar to previous studies on composite moment frames (Zhang et al., 2004; Zhou et al., 2007). Four-node shell elements located at the slab centerline defined the slab geometry. For simplicity, an elasto-plastic constitutive model with reduced concrete modulus $\left(0.33 \cdot E_{c}\right)$ and yield strength defined the concrete material behavior (similar to Zhang et al. (2004) and Zhou et al. (2007)). Calibration of the concrete constitutive behavior is presented in Prinz (2010) and was achieved using cyclic composite moment frame test data from Jones et al. (2002).

The interaction between the concrete slab and steel beams was modeled as a discrete connection using two linear springs and nodal displacement constraints. Two spring elements were oriented in the longitudinal and transverse beam directions to simulate the shear stiffness of a typical stud connector. A constraint joining the beam and slab nodes restricted relative vertical movement (see Figure 4). The stiffness of the linear springs was calculated using typical stud properties in the equation $K_{s}=$ $0.9 \cdot G_{s} \cdot A_{s} / L_{s}$; where $G_{s}, A_{s}$, and $L_{s}$ are the shear modulus, stud cross-sectional area, and stud length respectively.

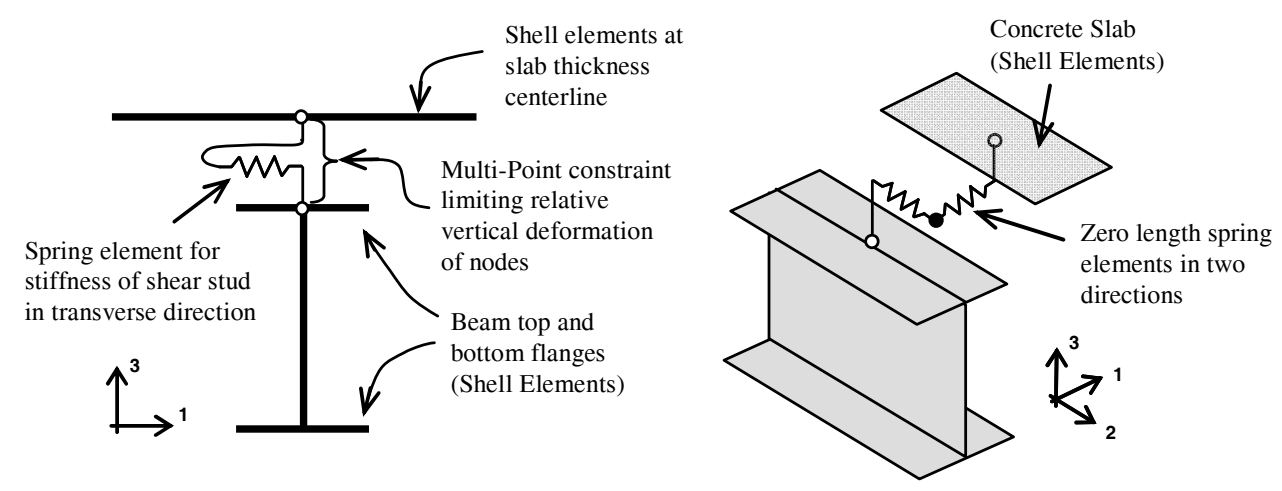

Figure 4. Modeling technique for slab-to-beam connection 
Frame Loading. Two acceleration time-histories were applied to each of the four EBF models, resulting in a total of 8 dynamic analyses. The two acceleration records chosen were taken from the 1989 Loma Prieta, California earthquake, and scaled such that the earthquake spectra matched the design response spectrum at the fundamental period of each frame (see Table 3 for record details). Note that only two acceleration records were chosen for this study, due to the large computational time and effort required for relatively refined-mesh dynamic analyses having shell elements.

In addition to lateral accelerations, factored floor gravity loads corresponding to $1.2 \mathrm{D}+0.5 \mathrm{~L}$ (ASCE, 2005) were applied to the $\mathrm{P}-\Delta$ column at each story.

Table 3: Chosen earthquake acceleration records

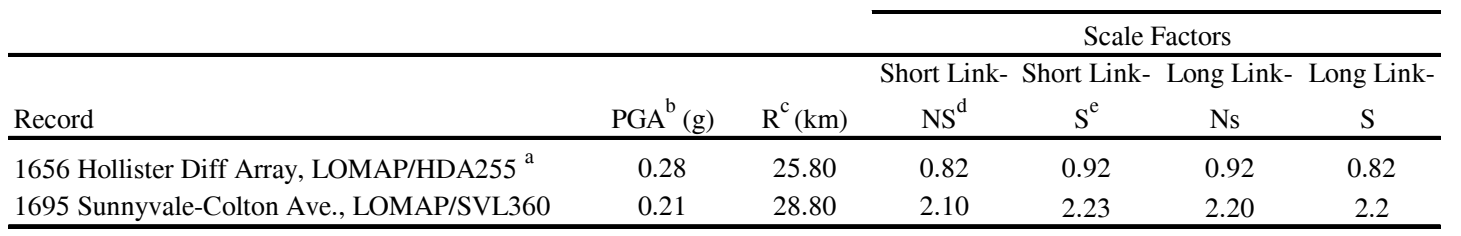

a. Designation in Pacific Earthquake Engineering (PEER) database

b. Peak ground acceleration

c. Distance to fault rupture

d. No slab

e. With slab

Cyclic Damage Model. An ultra low-cycle fatigue damage model based on a degraded significant plastic strain (DSPS) criterion (Kanvinde and Deierlein, 2004) was used to provide relative link damage information between each EBF model. The DSPS criterion is chosen for this study because model triaxialities remained relatively constant over the full range of plastic strains induced by the acceleration timehistories. In the DSPS criterion, failure is predicted once a significant plastic strain, $\varepsilon_{t}{ }^{*}$, exceeds the degraded critical plastic strain, $\varepsilon_{p, c r}{ }^{*}$, over a characteristic length, $l^{*}$ (note that $l^{*}$ is typically much smaller than the smallest element size used in this study). The significant plastic strain parameter represents the material demands with respect to void size, while the degraded critical plastic strain represents the remaining material capacity. Equations 1 and 2 represent the DSPS parameters $\varepsilon_{t}{ }^{*}$ and $\varepsilon_{p, c r}{ }^{*}$ respectively.

$\varepsilon_{t}^{*}=\varepsilon_{p, t}-\beta \cdot \varepsilon_{p, c}$

$\varepsilon_{p, c r}{ }^{*}=\exp \left(-\lambda_{d s p s}\left[\varepsilon_{p}\right]\right) \cdot \alpha \cdot \exp (-1.5 \cdot T)$

In Equation $1, \varepsilon_{p, t}$ and $\varepsilon_{p, c}$ are the integration of plastic strain under positive (tensile) and negative (compressive) triaxiality respectively, while $\beta$ is a weighting term (considered as 0.6 in this study) allowing for some material damage under compressive cycles. In Equation $2, \lambda_{d s p s}$ is a damageability parameter accounting for cyclic degradation [taken as -0.49 from cyclic coupon testing in Kanvinde and Deierlein (2004)], $\varepsilon_{p}$ is the accumulated equivalent plastic strain, $\alpha$ is a material specific parameter [taken as 2.9 from monotonic notched bar testing in Prinz and Nussbaumer (2012)], and $T$ is the triaxiality stress state (defined as the ratio between the hydrostatic pressure and von Mises stress). 


\section{RESULTS \& DISCUSSION}

System-Level Drift Comparison. Figure 5 shows the mean and individual peak inter-story drift values for each frame under each dynamic loading. With the exception of the first story short link models, models with concrete slabs experienced lower mean inter-story drift demands compared to bare-steel models. Mean drift values for the short link slab models were $7.2 \%$ and $12.1 \%$ lower at the second and third stories respectively; while first story drift values were slightly higher with slabs (only 2\% higher). Drift reductions due to the concrete slabs were more evident in the long link models, with $17.1 \%, 20.9 \%$, and $16.1 \%$ lower drift (based on mean values) in the first, second, and third stories.

Individual story drifts were slightly larger for the long link models as compared to the short link models. Peak inter-story drift under the LOMAP/SVL360 event was near $1.1 \%$ in the first story for the bare-steel long link models and $0.9 \%$ in the second story for the bare-steel short link models (see again Figure 5).
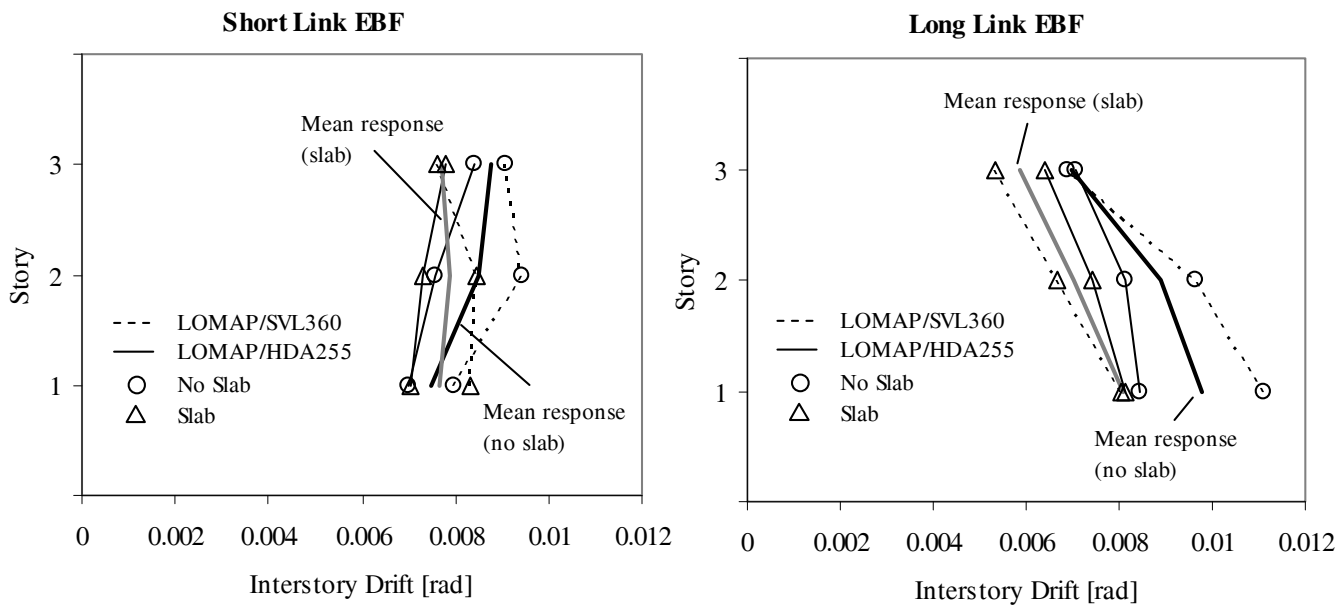

Figure 5. Peak inter-story drift for EBFs with and without slabs (both short link and long link designs).

Comparison of Link Rotation Demands. Models with concrete slabs experienced lower mean link rotation demands compared to equivalent bare-steel models. These slab effects are greater for the models containing large flexural yielding links. Figure 6 shows the peak link rotation demands at each story for the four frames analyzed. From Figure 6, mean first-story link rotation demands are 4.2\% lower for the short link models and $20.2 \%$ lower for the long link models when slabs were included. These link rotation reductions are directly related to added stiffness from the concrete slab, as the story mass did not change with the additional slab elements.

The highest link rotations occurred in the first story, under the LOMAP/SVL360 event. As expected from the similar inter-story drifts, long link rotations were lower than short link rotations, due to the longer link geometry. Peak rotation values for the short shear links were 0.043rad and 0.045rad for the slab and no slab models respectively. Peak rotation values for the long flexural links were $0.02 \mathrm{rad}$ and $0.03 \mathrm{rad}$ for the slab and no slab models respectively. 

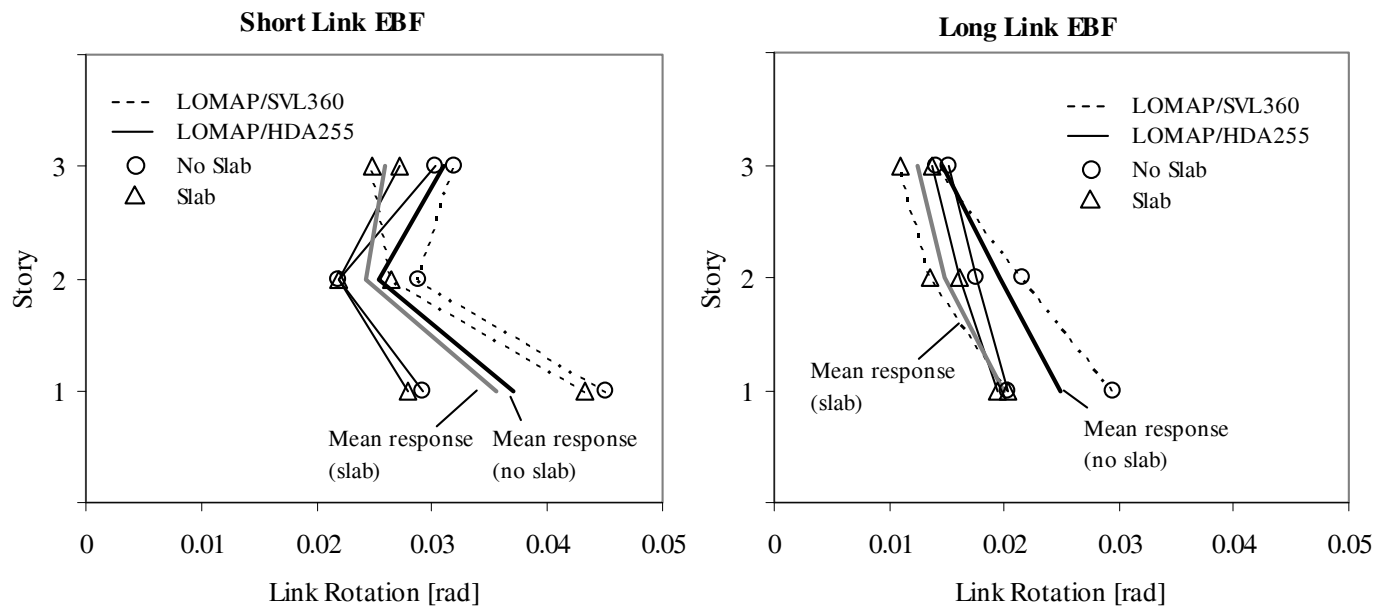

Figure 6. Link rotation demands

Gauging individual link rotation demands by cyclic experimental testing performed by others indicates little potential for link failure (fracture). Testing of Link-to-column specimen MWS (having post-Northridge welding details) by Okazaki et al. (2006) experienced link fracture only after reaching rotations of $0.05 \mathrm{rad}$. With peak link rotations being 0.045 for the short links in the analyses, it is likely that link fracture will not occur. Nevertheless, a later section will quantify the relative link damage accumulation based on the measured stress and strain states in the dynamic analyses.

Residual Frame Drifts. Similar to trends with inter-story drift and link rotation, mean residual frame drifts are lower for EBF models containing slabs (see Figure 7). Compared to their equivalent bare-steel models, short link slab models experienced $36.6 \%, 40.9 \%$, and $57.9 \%$ lower residual drift at the first, second, and third stories respectively. This suggests an increase in self-centering behavior for the short link slab models, as the link rotations and inter-story drift values are fairly similar in the lower stories. Similar reductions in residual drift were observed for the long link models containing slabs.
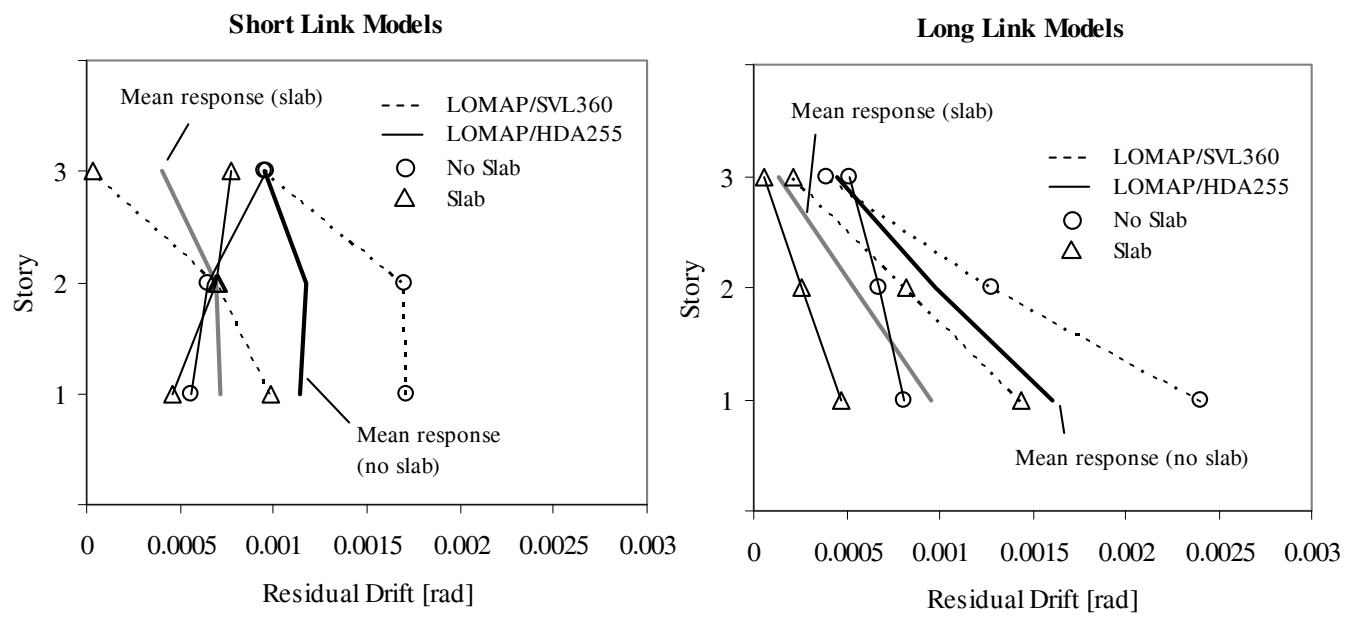

Figure 7. Residual drift for EBFs with and without slabs (both short link and long link designs). 
Accumulation of Link Damage. With the exception of the short link model during the LOMAP/HDA255 event, accumulation of link damage is similar between the slab and no slab models. Figure 8 shows the relationship between fatigue capacity and demand following the LOMAP/HDA255 event, along with reserve fatigue capacity values for each frame. All values are taken from the first story link which experienced the highest plastic demand. Even though link rotation demands were reduced due to added slab stiffness, damage accumulation remained relatively constant between the slab and no slab models due to increased plastic strains within the slab models. This plastic demand increase is presumably due to a neutral axis shift caused by the slab, producing higher strains toward the link bottom flange at lower rotation levels. Note in Figure 8(b) that the reserve fatigue capacity values simply provide relative comparison between the models to draw inferences into slab effects; and while an $\Omega$ value of 0 technically indicates fracture initiation, the level of mesh refinement used prevents such definitive predictions.

The observed decrease in damage for the short link slab model under the LOMAP/HDA255 event is due to a decrease in stress triaxiality within the critical region of the composite links (see Figure 9). From Equation 2, decreases in triaxiality lead to higher fatigue capacity (reduced void growth). Critical regions were identified to be within the link flange at the link-to-column connection, and link web near the brace-to-beam connection.
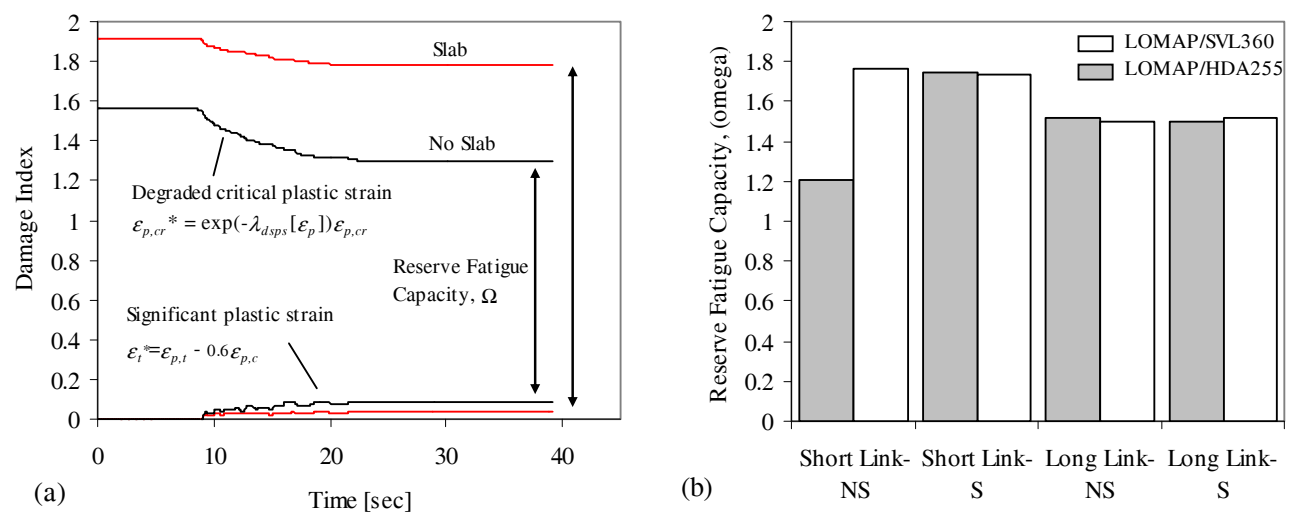

Figure 8. (a) Damage index comparison for short link EBF with and without slab from LOMAP/HDA255 event, and (b) reserve fatigue capacity comparison for all frames.

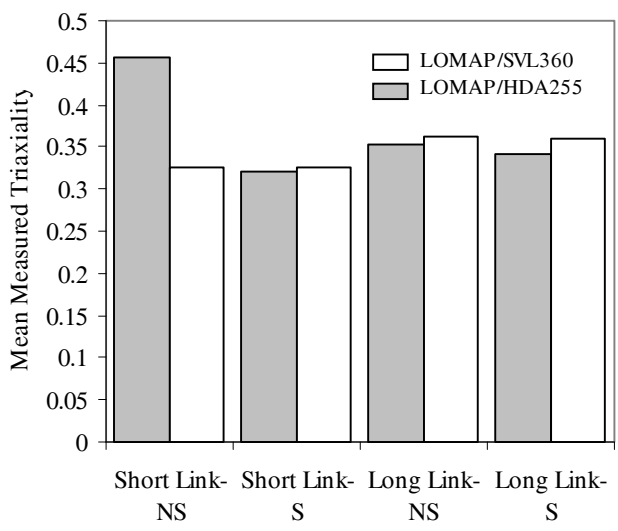

Figure 9. Comparison of mean stress triaxiality in critical link region. 


\section{CONCLUSIONS}

Two EBF designs, one having short (shear yielding) links and the other having long (flexural yielding) links, were considered as bare-steel systems and systems with concrete slabs to investigate relative slab effects on frame demands. Nonlinear dynamic time-history analyses using shell elements allowed for both system-level and local damage comparisons. Two design-level earthquake accelerations loaded the frames. A micro-mechanics based fatigue criterion allowed for relative link damage comparisons between the slab and bare-steel frames. Computer models indicate:

1. Mean system-level demands (inter-story drift, residual drift, and link rotations) are lower for composite EBFs compared to the equivalent bare-steel EBFs. Modal frequencies were greater for the composite EBFs, indicating increased system stiffness compared to the bare-steel frames.

2. Reductions in inter-story drift, residual drift, and link rotation were greatest for the long (flexural yielding) link configurations. Residual drift values for the long link models reduced more than $35 \%$ at all floor levels when the concrete slabs were added.

3. Even though frame drifts and link rotation demands were reduced due to added slab stiffness, link damage accumulation remained relatively constant between the slab and no slab models due to increased plastic strains within the composite links. This plastic demand increase is presumably due to a neutral axis shift, producing higher strains toward the link bottom flange at lower rotation levels.

\section{REFERENCES}

American Institute of Steel Construction, AISC (2005). Seismic provisions for structural steel buildings. Chicago.

ASCE (2005). "Minimum design loads for buildings and other structures." ASCE 705/ANSI A58: Reston, Va.

Chi, W.-M., El-Tawil, S., and Deierlein, G.G. (1998). "Inelastic analysis of a 17-story steel framed building damaged during Northridge." Eng. Structures 20(4-6): p. 481-495.

Clifton, C., Bruneau, M., MacRae, G., Leon, R., and Fussell, A. (2011). "Steel structures damage from the christchurch earthquake series of 2010 and 2011." Bulletin of the New Zealand Society for Earthquake Engineering 44(4): p. 297-318.

Foutch, D. A., and Yun, S.-Y. (2002). "Modeling of steel moment frames for seismic loads." J. Constructional Steel Research 58(5-8): p.529-564.

Gardiner, S., Clifton, G.C., and MacRae, G.A. (2013). "Performance, damage assessment and repair of a multistorey eccentrically braced framed building following the Christchurch earthquake series." Steel Innovations Conference 2013: Christchurch, New Zealand. 
Jones, S. W., Fry, G.T., and Engelhardt, M.D. (2002). "Experimental evaluation of cyclically loaded reduced beam section moment connection." J. Struct. Eng. 128(4): p. 441-451.

Kanvinde, A. M. and G. G. Deierlein (2004). "Micromechanical simulation of earthquake induced fractures in steel structures." Blume Center TR145 Stanford Univ., Stanford, Calif.

Kanvinde, A. M., Grilli, D.A., and Marshall, K. (2012). "A framework for forensic examination of earthquake-induced steel fracture based on the field failures in the 2011 Christchurch earthquake." Proc. 15th World Conference on Earthquake Engineering: Lisbon, Portugal.

Kaufmann, E. J., Metrovich, B.R., Pense, A.W. (2001). "Characterization of cyclic inelastic strain behavior on properties of A572 Gr. 50 and A913 Gr. 50 rolled sections." ATLSS Rep. No. 01-13. : Bethlehem (Pa), National Center for Engineering Research on Advanced Technology for Large Structural Systems, Lehigh Univ.

Okazaki, T., Engelhardt, M.D., Nakashima, M., and Suita, K. (2006). "Experimental performance of link-to-column connections in eccentrically braced frames." $J$. Struct. Eng. 132(8): 1201-1211.

Popov, E. P., and Ricles, J.M. (1988). "An experimental study of seismically resistant eccentricaly braced frames with composite floors." Proc. 9th World Conference on Earthquake Engineering: Tokyo-Kyoto, Japan, p. IV 273-278.

Prinz, G. S. (2010). "Using buckling-restrained braced frames in eccentric configurations." Ph.D. Dissertation: Brigham Young University, Provo, Utah.

Prinz, G. S. and A. Nussbaumer (2012). "Fatigue analysis of liquid-storage tank shellto-base connections under multi-axial loading." Engineering Structures 40(0): 75-82.

Richards, P. W. (2004). "Cyclic stability and capacity design of steel eccentrically braced frames." Ph.D. Dissertation.: University of California, San Diego.

Richards, P. W. (2009). "Seismic column demands in ductile braced frames." $J$. Struct. Eng. 135(1): p. 33-41.

Richards, P. W., and Uang, C-m. (2006). "Testing protocol for short links in eccentrically braced frames." J. Struct. Eng. 132(8): p. 1183-1191.

Ricles, J. M., and Popov, E.P. (1994). "Inelastic link element for EBF seismic analysis." J. Struct. Eng. 120(2): p. 441-463.

Tremblay, R., and Robert, N. (2001). "Seismic performance of low- and medium-rise chevron braced steel frames." Can. J. Civil Eng. 28(4): p. 699-714.

Zhang, X., Ricles, J.M., Lu, L.-W., and Fisher, J.W. (2004). "Analytical and experimental studies on seismic behavior of deep column-to-beam welded reduced beam section moment connections." 13th World Conference on Earthquake Engineering, Vancouver, B.C., Canada, Paper No. 1599.

Zhou, F., Moslam, K.M., and Masayoshi, N. (2007). "Finite-element analysis of a composite frame under large lateral cyclic loading." J. Struct. Eng. 133(7): p. 1018-1026. 